\title{
Psychogenic (Functional) Jaw-Opening Dystonia: Three Case Reports and a Comparison of Symptomatic Jaw-Opening Dystonia Associated with Organic Causes in the Literature
}

\section{Won Tae Yoon ${ }^{1 *}$ and Eung Seok Oh}

${ }^{1}$ Department of Neurology, Kangbuk Samsung Hospital, Sungkyunkwan University School of Medicine, Seoul, Republic of Korea

${ }^{2}$ Department of Neurology, Chungnam National University Hospital, Chungnam National University School of Medicine, Daejeon, Republic of Korea

\begin{abstract}
Background: Jaw-opening dystonia is very rarely reported, and involuntary jaw-opening dystonia as an initial manifestation of psychogenic (functional) movement disorder has not yet been reported. This study aimed to report unusual cases of psychogenic (functional) jaw-opening dystonia and to compare the clinical patterns between organic and psychogenic (functional) jaw-opening dystonia.

Method: We enrolled three psychogenic (functional) movement disorder patients presenting involuntary severe jaw-opening dystonia as an initial manifestation. Moreover, we review previously reported cases and analyze the clinical pattern of organic psychogenic (functional) jaw-opening dystonia in comparison with our cases.

Results: Among 10 cases, including our cases, the most common pattern of organic jaw-opening dystonic symptoms was the sustained pattern. By contrast, all three patients with psychogenic (functional) jaw-opening dystonia presented with a paroxysmal pattern. The major neuro-radiologically associated localizations of organic jaw-opening dystonia were the cerebellum and basal ganglia. Sensory feedback or "sensory tricks" were only observed in organic jaw-opening dystonia.

Conclusion: The results of this clinically investigative study may provide support for the differential diagnosis of jaw-opening dystonia between organic and psychogenic (functional) etiologies. Additionally, if paroxysmal jawopening dystonia combined with inconsistent, incongruous hyperkinetic movement symptoms is present, diagnosis of a psychogenic (functional) movement disorder should be considered.
\end{abstract}

Keywords: Jaw-opening dystonia; Psychogenic; Organic; Sensory trick; Botulinum toxin

\section{Introduction}

Jaw-opening dystonia (oromandibular dystonia with jawopening) is a relatively rare condition among hyperkinetic movement symptoms. Generally, almost irregular, involuntary wide opening of mouth characterizes the presentation of jaw-opening dystonia regardless of temporo-mandibular joint problems or peripheral lesions of the oromandibular area. In the literature from the 1970s until now, jaw-opening dystonia has been reported in only a limited number of case reports [1-9]. However, most of previously reported cases did not present proven causes of the jaw-opening dystonia, and thus the clinical etiologies might be described as idiopathic. For these reasons, many patients with jaw-opening dystonia may remain undiscovered or misdiagnosed as has occurred in some case reports [10,11]. The pathophysiology and etiology of jaw-opening dystonia remain unclear, but some possible pathophysiological mechanisms or peripheral causes have been suggested for some cases [2,4]. Moreover, in some cases, the jaw-opening dystonia presumably had a central origin, e.g., focal brain lesion, ischemic stroke, neurodegenerative disease, or metabolic or genetic disorders with structural brain involvement [10-17]. However, secondary jaw-opening dystonia associated with a central lesion is extremely rare, and psychogenic (functional) movement disorder initially presenting as jaw-opening dystonia has not been reported in the literature. The aim of this work is not only to report on the heretofore un-reported clinically unusual phenotype of psychogenic (functional) movement disorder initially presenting as jaw-opening dystonia but also to compare this condition with the clinical characteristic patterns of jaw-opening dystonia that have previously been reported in the literature and were possibly associated with central origins or caused by central lesions.

\section{Material and Methods}

\section{Data acquisition and patients}

Based on consultation with the psychiatric departments and emergency rooms of our hospitals, we identified three patients with severe jaw-opening dystonia presenting with initially hyperkinetic movement symptoms. Written informed consent was obtained from all three patients for the publication of all clinical results, videotapes, and photographs of the dystonic symptoms for this article.

Furthermore, the PubMed database was screened for jaw-opening dystonia-related articles from 1970 to August 2017 via searches for the following terms: "jaw opening dystonia", "jaw-opening dystonia", "jaw dystonia", and "oromandibular dystonia". The results of this screening of the PubMed database yielded 632 articles overall (the respectively searched terms yielded 54, 44, 218 and 316 articles). Among these articles, only seven cases with organic causes that presented with jawopening dystonia were included in the analysis. The inclusion criterion

*Corresponding author: Won Tae Yoon, Kangbuk Samsung Hospital, Sungkyunkwan University School of Medicine, Seoul, Republic of Korea, Tel: 82-22001-1938; E-mail:wtyoon@gmail.com

Received September 18, 2017; Accepted October 15, 2017; Published October 18, 2017

Citation: Yoon WT, Oh ES (2017) Psychogenic (Functional) Jaw-Opening Dystonia: Three Case Reports and a Comparison of Symptomatic Jaw-Opening Dystonia Associated with Organic Causes in the Literature. J Neurol Disord 5: 365 doi:10.4172/2329-6895.1000365

Copyright: @ 2017 Yoon WT, et al. This is an open-access article distributed under the terms of the Creative Commons Attribution License, which permits unrestricted use, distribution, and reproduction in any medium, provided the original author and source are credited. 
was as follows: reported cases presenting with psychogenic (functional) jaw-opening dystonia and/or symptomatic dystonia presumably associated with organic causes. We excluded the reported cases that presented with jaw-opening dystonia associated with drug-induced, tardive, or idiopathic dystonia and undescribed cases that focused on the detailed neuro-radiological findings.

\section{Statistical analysis}

The collected data were analyzed via descriptive statistics (absolute and relative frequencies). Continuous variables are expressed as the means \pm the standard deviations (SDs) and categorical variables are expressed as percentages.

\section{Results}

\section{Case Presentation}

\section{Case 1}

A 49-year-old Korean woman was referred to our neurologic department due to involuntary hyperkinetic movements of the jaw. She presented with relatively acute-onset, repetitive, involuntary opening of the mouth one day previously. She developed clinically non-fixed, paroxysmal jaw-opening dystonia and hypertonia of the jaw and mouth that disappeared with distraction (Video Segment 1).

Other neurological examinations, routine laboratory tests and brain imaging were normal. Additionally, a psychological examination revealed a severe stressful condition and depression. In our department, she was clinically diagnosed with psychogenic (functional) hyperkinetic movement disorder presenting as jaw-opening dystonia. After three days of placebo medication and supportive care, her dystonic symptoms fully improved, and there was no recurrence of jaw opening dystonia (Video Segment 2).

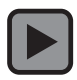

Video Segment 1: Case 1 exhibited irregular, involuntary paroxysmal jaw-opening dystonia with hypertonia of the jaw and mouth that occurred simultaneously with cervical dystonia.

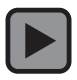

Video Segment 2: After 3 days of placebo medication and supportive care, this patient's jaw-opening dystonia and other dystonic symptoms were fully resolved.

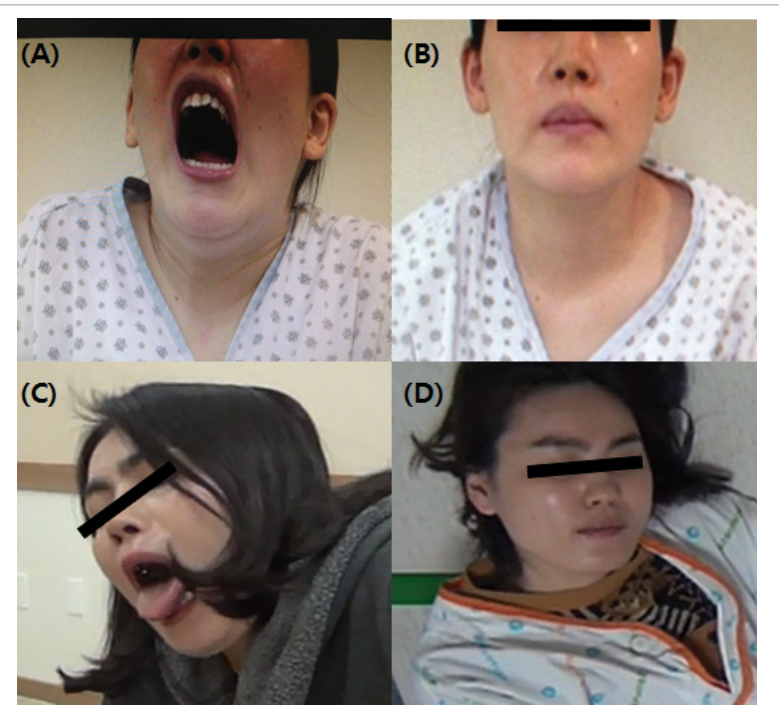

Figure 1: (A) Case 2 exhibited irregular, involuntary paroxysmal jaw-opening dystonia. (B) The hypertonia of the jaw and mouth of case 2 disappeared with distraction. (C) Case 3 exhibited irregular, involuntary paroxysmal jaw-opening dystonia with lingual protruding dystonia or vocalizations. (D) After supportive care and some medications, her paroxysmal dystonic symptoms fully improved.

\section{Case 2}

A 38-year-old Korean woman was referred to our neurologic department due to involuntary hyperkinetic movements of the mouth and upper limbs. She presented with involuntary opening of the mouth and irregular dystonic tremors of the upper limbs in a post-natal state after delivery. She also developed a clinically similar type of jawopening dystonia (Figure 1A). Her chief complaints of hyperkinetic movement symptoms included non-fixed, paroxysmal jaw-opening dystonia and, like the first case, the hypertonia of the jaw and mouth disappeared with distraction (Figure 1B).

Other neurological examinations, routine blood laboratory tests and brain imaging were normal. Additionally, a psychological examination revealed severe postpartum depression. In our department, she was also clinically diagnosed with psychogenic (functional) hyperkinetic movement disorder presenting with jaw-opening dystonia and limb dystonia. After an initial three days of placebo medication and supportive care, her dystonic symptoms gradually improved. She then took low-dose alprazolam, and there was no recurrence of the jawopening dystonia.

\section{Case 3}

A 37-year-old Korean woman was referred to our neurologic department due to paroxysmal, repetitive, involuntary generalized hyperkinetic movements. Three years ago, she initially presented with involuntary movement of her nose, such as whimpers. Subsequently, these involuntary movements slowly progressed to the mouth, jaw, neck, hand, leg and trunk and were primarily right lateralized. The clinical patterns of the paroxysmal hyperkinetic movements were not always same, and her involuntary movement symptoms occurred irregularly at rest or when she was moving.

Her dystonic symptoms, including jaw-opening dystonia, continued in bouts of approximately three minutes (Figure 1C). For an exact differential diagnosis, she was admitted to the epilepsy monitoring unit (EMU) for 24 hours of video EEG monitoring. During the EMU monitoring, we observed various, bizarre, abnormal symptoms and hyperkinetic movements including limb hyperextension, lingual 


\begin{tabular}{|c|c|c|c|c|c|c|}
\hline $\begin{array}{l}\text { Causative } \\
\text { factor } \\
\text { [Reference] }\end{array}$ & $\begin{array}{c}\text { Gender/Age } \\
\text { Dystonia pattern }\end{array}$ & Final diagnosis & $\begin{array}{l}\text { Neuro-radiological } \\
\text { localizations }\end{array}$ & $\begin{array}{l}\text { Combined dystonia } \\
\text { or neurologic abnormality }\end{array}$ & $\begin{array}{l}\text { Response } \\
\text { of sensory } \\
\text { feedback }\end{array}$ & $\begin{array}{l}\text { Treatment } \\
\text { for dystonia }\end{array}$ \\
\hline $\begin{array}{c}\text { Organic } \\
{[10]}\end{array}$ & $\begin{array}{c}F / 72 \\
\text { Sustained }\end{array}$ & $\begin{array}{l}\text { Pontine lesion } \\
\text { (small, old } \\
\text { infarction) }\end{array}$ & $\begin{array}{l}\text { Pontine reticular formation } \\
\text { on the right side }\end{array}$ & $\begin{array}{l}\text { Rhythmic dystonia in digastric } \\
\text { muscles (or "myorhythmia") }\end{array}$ & Yes (by hand) & Botulinum toxin \\
\hline $\begin{array}{c}\text { Organic } \\
{[11]}\end{array}$ & $\begin{array}{c}\mathrm{M} / 40 \\
\text { Paroxysmal }\end{array}$ & Brain anomalies & $\begin{array}{l}\text { Cavum septi pellucidi } \\
\text { and Verga's ventricle }\end{array}$ & Dysarthria, profuse drooling & ${ }^{*} \mathrm{NA}$ & $\begin{array}{l}\text { Diazepam, } \\
\text { Clonazepam }\end{array}$ \\
\hline $\begin{array}{c}\text { Organic } \\
{[12]}\end{array}$ & $\begin{array}{c}\mathrm{M} / 20 \\
\text { Sustained }\end{array}$ & $\begin{array}{l}\text { Hallervorden-Spatz } \\
\text { syndrome }\end{array}$ & Bilateral globus pallidus & $\begin{array}{l}\text { Painful mandibular joint subluxation, } \\
\text { distal limb dystonia and } \\
\text { choreoathetosis }\end{array}$ & NA & Botulinum toxin \\
\hline $\begin{array}{c}\text { Organic } \\
{[13]}\end{array}$ & $\begin{array}{c}\mathrm{F} / 70 \\
\text { Sustained }\end{array}$ & $\begin{array}{l}\text { Neuro-Behcet's } \\
\text { syndrome }\end{array}$ & $\begin{array}{l}\text { Brainstem, bilateral basal } \\
\text { ganglia, deep white } \\
\text { matter, right frontal cortex }\end{array}$ & $\begin{array}{l}\text { Chorea, ataxia, dysarthria, } \\
\text { anisocoria, vertical gaze limitation }\end{array}$ & NA & Botulinum toxin \\
\hline $\begin{array}{c}\text { Organic } \\
{[14]}\end{array}$ & NA & $\begin{array}{l}\text { Primary cerebellar } \\
\text { degenerative } \\
\text { disease }\end{array}$ & Bilateral cerebellum & NA & NA & Botulinum toxin \\
\hline $\begin{array}{c}\text { Organic } \\
{[15]}\end{array}$ & $\begin{array}{c}\text { F/65 } \\
\text { Continual }\end{array}$ & $\begin{array}{l}\text { Cerebellar } \\
\text { ischemic stroke }\end{array}$ & $\begin{array}{l}\text { Left cerebellum } \\
\text { (left } † \text { AICA territory) }\end{array}$ & $\begin{array}{l}\text { Lingual and perioral dystonia, } \\
\text { left-sided ataxia }\end{array}$ & $\begin{array}{l}\text { Yes (by nip } \\
\text { something) }\end{array}$ & Botulinum toxin \\
\hline $\begin{array}{c}\text { Organic } \\
{[16]}\end{array}$ & $\begin{array}{c}\mathrm{M} / 16 \\
\text { Sustained }\end{array}$ & $\ddagger$ PKAN & Bilateral globus pallidus & $\begin{array}{l}\text { Following hands and extremities } \\
\text { dystonia after } 3 \text { years }\end{array}$ & $\begin{array}{c}\text { Yes } \\
\text { (by hand) }\end{array}$ & Botulinum toxin \\
\hline $\begin{array}{l}\text { Functional } \\
\text { [present case] }\end{array}$ & $\begin{array}{c}F / 49 \\
\text { Paroxysmal }\end{array}$ & $\begin{array}{l}\text { Psychogenic } \\
\text { (Functional) jaw- } \\
\text { opening dystonia }\end{array}$ & Normal & Simultaneous cervical dystonia & No & Reassurance \\
\hline $\begin{array}{l}\text { Functional } \\
\text { [present case] }\end{array}$ & $\begin{array}{c}\mathrm{F} / 38 \\
\text { Paroxysmal }\end{array}$ & $\begin{array}{l}\text { Psychogenic } \\
\text { (Functional) jaw- } \\
\text { opening dystonia }\end{array}$ & Normal & $\begin{array}{l}\text { Bizarre hyperkinetic movements } \\
\text { of limbs and trunk }\end{array}$ & No & Alprazolam \\
\hline $\begin{array}{c}\text { Functional } \\
\text { [present case] }\end{array}$ & $\begin{array}{c}F / 37 \\
\text { Paroxysmal }\end{array}$ & $\begin{array}{l}\text { Psychogenic } \\
\text { (Functional) jaw- } \\
\text { opening dystonia }\end{array}$ & Normal & $\begin{array}{l}\text { Bizarre hyperkinetic movements } \\
\text { of tongue, limbs and trunk }\end{array}$ & No & $\begin{array}{l}\text { Alprazolam } \\
\text { Clonazapam }\end{array}$ \\
\hline
\end{tabular}

Table 1: Summary of clinical characteristics and neuro-radiological localizations in reported cases of organic jaw-opening dystonia and present cases of psychogenic (functional) jaw-opening dystonia.

protruding dystonia, vocalizations, improper hand movements and truncal posture as well as paroxysmal jaw-opening dystonia, truncal dystonia and limb dystonia. Moreover, we confirmed that the frequency and duration of the paroxysmal events decreased dramatically after placebo treatment for which she and her family consented. Other neurological examinations, routine blood laboratory tests, brain imaging, electrophysiological tests and genetic tests related to dystonia were all normal. She was also clinically diagnosed with psychogenic (functional) hyperkinetic movement disorder presenting with jawopening dystonia, truncal dystonia and limb dystonia. After supportive care and some medications including alprazolam and clonazepam, her paroxysmal dystonic symptoms fully improved (Figure 1D).

Comparisons of the clinical patterns of our 3 cases of psychogenic (functional) jaw-opening dystonia and previously reported cases of jaw-opening dystonia associated with organic causes

Together with our three cases and the data from the reviewed literature, we identified 10 cases of clinically confirmed jaw-opening dystonia and summarized the clinical profiles of the 10 cases (Table 1) $[10-16]$. In the literature, there were no cases of psychogenic (functional) jaw-opening dystonia that were like our cases. Excluding one case due to the absence of demographic data, there were 3 women and 3 men (mean age $47.2 \pm 25.4$ years; range 16 to 72 years) in the organic jaw-opening dystonia group. In contrast, all three patients in the psychogenic (functional) jaw-opening dystonia group were women (mean age $41.3 \pm 6.7$ years; range 37 to 49 years). In the organic jawopening dystonia group, the most common pattern of jaw-opening dystonic symptoms was a sustained pattern. In contrast, all three patients in the psychogenic (functional) group presented with a paroxysmal pattern of jaw-opening dystonia.
Major associated neuro-radiological localizations of the organic jaw-opening dystonia cases were the cerebellum and basal ganglia (especially the bilateral globus pallidus), and the related disorders were neuro-vascular, neurodegenerative, neurogenetic, and metabolic diseases that included ischemic stroke, primary brain degenerative disease, pantothenate kinase-associated neurodegeneration, and neuro-Behcet's disease. Most of the cases in the organic jaw-opening dystonia group were accompanied by typical, focal neurologic signs and symptoms such as ataxia, dysarthria and brainstem signs. Among the six cases with documented responses related to sensory feedback or "sensory tricks" among the jaw-opening dystonic symptoms, only three cases in the organic jaw-opening dystonia group exhibited responses to sensory feedback. Although most of the cases in the organic jawopening dystonia group receive botulinum toxin injections as the treatment of choice, we consider prosthetic dental devices as another therapeutic option for patients who seem to be resistant to botulinum toxin treatment based on these results about sensory feedback or "sensory tricks" in jaw-opening dystonic symptoms and previous studies of the treatment of jaw-opening dystonia using some device $[14,18,19]$.

\section{Discussion}

To date, few studies of jaw-opening dystonia have been reported; however, to the best of our knowledge, our psychogenic (functional) jaw-opening dystonia cases are the first to be reported as initial manifestations of psychogenic movement disorders. Moreover, this comparison study of the clinical characteristics and dystonic patterns of our cases and cases of organic jaw-opening dystonia from the literature is the first report of such comparisons. Although there are some limitations of the clinical data in the previously reported cases, and we were unable to conduct statistical analyses due to the small amount of clinical data, we presume some clinically important 
differences between organic jaw-opening dystonia and psychogenic (functional) jaw-opening dystonia based on this study. Whereas the distributions of gender and age in the organic jaw-opening dystonia group were variable, all three patients in the psychogenic (functional) jaw-opening dystonia group were women and their middle 30s to 40s. From the demographic perspective, psychogenic (functional) jawopening dystonia is likely more prevalent among women in their 30 s to 40 s, and organic jaw-opening dystonia occurs independently of gender at variable ages ranging from the teenage years to older than 60 years.

In view of the phenomenology and neurologic examinations, organic jaw-opening dystonia manifested with generally sustained or continual dystonic patterns and one or two segmental dystonia types. Additionally, we observed that major neurological abnormalities or focal neurologic signs and deficits accompanied the organic jawopening dystonia. In contrast, psychogenic (functional) jaw-opening dystonia typically manifested with paroxysmal dystonia patterns and multiple, but non-correlated, dystonia types. Moreover, there were no major neurological abnormalities or focal neurologic signs and deficits, and we observed accompanying inconsistent, incongruous bizarre movement symptoms and exhaustion or excessive fatigue with jaw-opening dystonia. Based on our three cases that presented with psychogenic (functional) jaw-opening dystonia, we expect that the risk factors for psychogenic (functional) jaw-opening dystonia might be associated with severely stressful conditions, anxiety disorder, and depression or postpartum depression. These clinically supportive factors could be helpful in the differential diagnosis between organic jaw-opening dystonia and psychogenic (functional) jaw-opening dystonia.

The pathomechanism and neurobiological basis for jaw-opening dystonia have not yet been clearly defined. In terms of the process of dystonia, one study implicated the modulation of cortical excitability by cerebellar outputs via the basal ganglia-thalamo-cortical network [20]. Moreover, another study suggested that GABAergic inhibition in the primary motor cortex mediated by the cerebello-thalamo-cortical network may be deficient in dystonia and those cerebellar outputs may alter basal ganglia activity and lead to dystonic movements [21].

\section{Conclusion}

To our knowledge, this is the first report of psychogenic (functional) movement disorders that initially present as jaw-opening dystonia and the first investigation and comparison of the clinical patterns and characteristics of organic and psychogenic jaw-opening dystonia for differential diagnosis. Based on this study, the presence of paroxysmal jaw-opening dystonia combined with inconsistent, incongruous hyperkinetic movement symptoms without focal neurologic signs and sensory tricks should lead to consideration of a psychogenic (functional) movement disorder diagnosis.

\section{References}

1. Paulson GW (1972) Meige's syndrome. Dyskinesia of the eyelids and facial muscles. Geriatrics 27: 69-73.

2. Schrag A, Bhatia KP, Quinn NP, Marsden CD (1999) Atypical and typical cranial dystonia following dental procedures. Mov Disord 14: 492-496.

3. Yoshida K, Kaji R, Kubori T, Kohara N, lizuka T, et al. (1998) Muscle afferent block for the treatment of oromandibular dystonia. Mov Disord 13: 699-705.

4. Sankhla C, Lai EC, Jankovic J (1998) Peripherally induced oromandibular dystonia. J Neurol Neurosurg Psychiatry 65: 722-728.

5. Loh HS (1983) Idiopathic oromandibular dystonia causing failure of mouth closure. Br Dent J 154: 291-292.

6. Marsden CD (1976) Blepharospasm-oromandibular dystonia syndrome (Brueghel's syndrome). A variant of adult-onset torsion dystonia? J Neurol Neurosurg Psychiatry 39: 1204-1209.

7. Gilbert GJ (1996) Brueghel syndrome: Its distinction from Meige syndrome Neurology 46: 1767-1769.

8. Gray AR, Barker GR (1991) Idiopathic blepharospasm-oromandibular dystonia syndrome (Meige's syndrome) presenting as chronic temporomandibular joint dislocation. Br J Oral Maxillofac Surg 29: 97-99.

9. Garcia-Albea E, Franch O, Munoz D, Ricoy JR (1981) Brueghel's syndrome report of a case with postmortem studies. J Neurol Neurosurg Psychiatry 44: 437-440.

10. Dietrichs E, Heier MS, Nakstad PH (2000) Jaw-opening dystonia presumably caused by a pontine lesion. Mov Disord 15: 1026-1028.

11. Miyaoka T, Miura S, Seno H, Inagaki T, Horiguchi J (2003) Jaw-opening dystonia (Brueghel's syndrome) associated with cavum septi pellucidi and Verga's ventricle - A case report. Eur J Neurol 10: 727-729.

12. Dressler D, Wittstock M, Benecke R (2001) Botulinum toxin for treatment of jaw opening dystonia in Hallervorden-Spatz syndrome. Eur Neurol 45: 287-288.

13. Revilla FJ, Racette BA, Perlmutter JS (2000) Chorea and jaw-opening dystonia as a manifestation of NeuroBehcet's syndrome. Mov Disord 15: 741-744.

14. Gonzalez-Alegre P, Schneider RL, Hoffman H (2014) Clinical, etiological, and therapeutic features of jaw-opening and jaw-closing oromandibular dystonias: A decade of experience at a single treatment center. Tremor Other Hyperkinet $\operatorname{Mov}(N$ Y) 4: 231.

15. Akin A, Yilmaz R, Selcuk F, Akbostanci MC (2014) Sudden onset of oromandibular dystonia after cerebellar stroke. Tremor Other Hyperkinet Mov (NY) 4: 262.

16. Yapici Z, Akcakaya NH, Tekturk P, Iseri SA, Ozbek U (2016) A novel gene mutation in PANK2 in a patient with severe jaw-opening dystonia. Brain Dev 38: 755-758.

17. Teive HA, Kluppel LE, Munhoz RP, Becker N, Muller PR, et al. (2012) Jawopening oromandibular dystonia secondary to Wilson's disease treated with botulinum toxin type A. Arq Neuropsiquiatr 70: 407-409.

18. Schneider R, Hoffman HT (2011) Oromandibular dystonia: A clinical report. J Prosthet Dent 106: 355-358.

19. Maestre-Ferrin L, Burguera JA, Penarrocha-Diago M, Penarrocha-Diago $M$ (2010) Oromandibular dystonia: A dental approach. Med Oral Patol Oral Cir Bucal 15: e25-27.

20. Daskalakis ZJ, Paradiso GO, Christensen BK, Fitzgerald PB, Gunraj C, et al. (2004) Exploring the connectivity between the cerebellum and motor cortex in humans. J Physiol 557: 689-700.

21. Neychev VK, Gross RE, Lehericy S, Hess EJ, Jinnah HA (2011) The functional neuroanatomy of dystonia. Neurobiol Dis 42: 185-201. 